\title{
Semi-solid-state fermentation: A promising alternative for neomycin production by the actinomycete Streptomyces fradiae
}

\author{
Isabel Machado ${ }^{\mathrm{a}, 2}$, José A. Teixeira $^{\mathrm{b}}$, Susana Rodríguez-Couto ${ }^{\mathrm{a}, *, 1}$ \\ a Department of Chemical Engineering, Rovira i Virgili University, Av. Països Catalans 26, 43007 Tarragona, Spain \\ ${ }^{\mathrm{b}}$ Institute for Biotechnology and Bioengineering (IBB), Centre of Biological Engineering, University of Minho, Campus de Gualtar, 4710-057 Braga, Portugal
}

\section{A R T I C L E I N F O}

\section{Article history:}

Received 15 January 2013

Received in revised form 27 March 2013

Accepted 28 March 2013

Available online 6 April 2013

\section{Keywords:}

Neomycin

Streptomyces fradiae

Semi-solid-state fermentation

Submerged fermentation

Staphylococcus epidermidis

\begin{abstract}
A B S T R A C T
The production of neomycin by the actinomycete Streptomyces fradiae, under semi-solid-state fermentation conditions was the main subject of this study. Two supports (nylon sponge and orange peelings) were tested in order to determine the most suitable one for the production of neomycin by the abovementioned microorganism. Nylon sponge led to the highest neomycin production, reaching a maximum value of $13,903 \mu \mathrm{g} / \mathrm{mL}$ on the 10 th day of cultivation. As a control, the same experiment was performed under submerged fermentation (SmF) conditions, without solid support. Here the production of neomycin by $S$. fradiae was about 55-fold lower (i.e. $250 \mu \mathrm{g} / \mathrm{mL}$ ) than that obtained for SSF.
\end{abstract}

(c) 2013 Elsevier B.V. All rights reserved.

\section{Introduction}

Neomycin (Fig. 1) is an important antibiotic, which belongs to the aminoglycoside family. It is widely applied in pharmaceutical preparations for local applications and in the veterinary practice. It was discovered in 1949 by the microbiologist Selman Waksman and his student Hubert Lechevalier, who isolated the neomycin-producing bacterium Streptomyces fradiae (Waksman and Lechevalier, 1949). Much later, a new neomycin-producer identified as Streptomycens marinensis was found (Sambamurthy and Ellaiah, 1974). This antibiotic is effective against Gram-negative, Gram-positive and acid fast bacteria.

Neomycin has a spectrum of antibiotic activity higher than that of penicillin, streptomycin and bacitracin and, although not being active against fungi is, beyond bacteriostatic, bactericidal, killing the cells against which it acts (Waksman and Lechevalier, 1949). In its sulphate form, as mainly used, neomycin comprises a mixture of three structurally-related compounds: neomycin A

\footnotetext{
* Corresponding author at: CEIT, Unit of Environmental Engineering, Paseo Manuel de Lardizábal 15, 20018 San Sebastian, Spain. Tel.: +34 943 212800x2239; fax: +34943213076.

E-mail address: srodriguez@ceit.es (S. Rodríguez-Couto).

1 IKERBASQUE, Basque Foundation for Science, Alameda de Urquijo 36, 48011 Bilbao, Spain.

2 Current address: Institute for Polymer Materials (Polymat), University of the Basque Country (UPV/EHU), Avda. de Tolosa 72, 20018 Donostia-San Sebastian, Spain.
}

(usually referred to as neamine), neomycin B (also known as framycetin) and neomycin C (Fig. 1). Neomycin B is the main component of the mixture and has the highest antibiotic activity. Neomycin $C$ is the less active minor component. Neomycin $A$ is the hydrolytic degradation product of neomycin $B$ and $C$ and has only $10 \%$ of the antibiotic activity of the major components (Yuan et al., 2006).

Neomycin is commercially produced by submerged fermentation $(\mathrm{SmF})$. However, this process requires high energetic expenditures. In the search for more economical fermentation processes with high antibiotic activity, solid-state fermentation (SSF) appears as an attractive alternative. Thus, Ellaiah et al. (2004) showed that SSF led to higher neomycin production than SmF by a mutant strain of Streptomyces marinensis. In addition, SSF is claimed to be more cost-effective than SmF. Thus, Castilho et al. (2000) found that the production of lipase by Penicillium restrictum resulted economically more advantageous in SSF than in SmF. More recently, Osma et al. (2011) have shown that the cost of producing the enzyme laccase by the white-rot fungus Trametes pubescens was 50 -fold lower in semi-solid-sate fermentation conditions than in SmF.

SSF is defined as any fermentation process in which microorganisms grow on solid support materials in the absence of free-flowing water (Pandey, 1992). Two types of solid supports can be used in SSF: natural supports (e.g. lignocellulosic wastes) and inert supports (e.g. plastic foams). SSF has gained much interest in recent years due to the advantages that presents over $\mathrm{SmF}$ such as higher product yields, less energy requirements, 


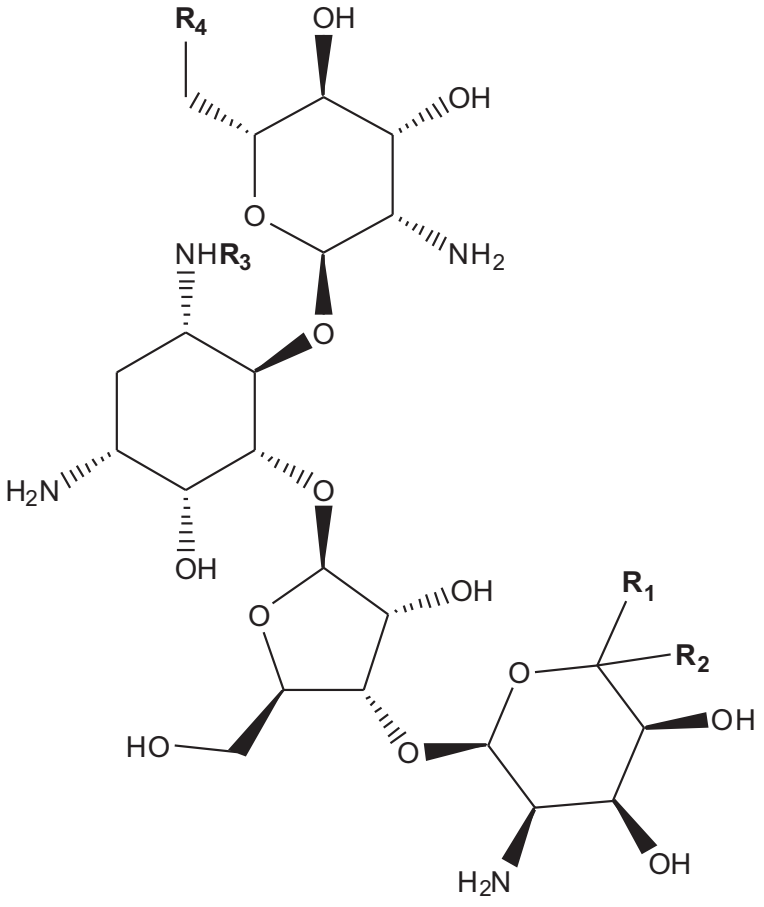

Fig. 1. Molecular structure of the main components of neomycin. Neomycin $\mathrm{B}$ when $\mathrm{R}_{1}=\mathrm{H}, \mathrm{R}_{2}=\mathrm{CH}_{2} \mathrm{NH}_{2}, \mathrm{R}_{3}=\mathrm{H}, \mathrm{R}_{4}=\mathrm{NH}_{2}$; neomycin $\mathrm{C}$ when $\mathrm{R}_{1}=\mathrm{CH}_{2} \mathrm{NH}, \mathrm{R}_{2}=\mathrm{H}, \mathrm{R}_{3}=\mathrm{H}$, $\mathrm{R}_{4}=\mathrm{NH}_{2}$; and neomycin $\mathrm{A}$ (or neamine) when the structure is only constituted by rings of $\mathrm{R} 3$ and $\mathrm{R} 4, \mathrm{R}_{3}=\mathrm{H}, \mathrm{R}_{4}=\mathrm{NH}_{2}$.

easier aeration, less wastewater generation, reduced bacterial contamination and easier product recovery (Pandey et al., 2000). Hence, in the present paper the production of neomycin by $S$. fradiae grown under semi-solid-state fermentation conditions was investigated. This type of fermentation is a sort of SSF in which the free liquid content has been increased in order to facilitate nutrient availability and fermentation control (Rodriguez-Couto et al., 2002; Economou et al., 2010). To the best of our knowledge the production of neomycin by $S$. fradiae under semi-solidstate fermentation conditions has not been reported before this study.

\section{Materials and methods}

\subsection{Microorganisms}

Streptomyces fradiae DSMZ 40063 was obtained from the German Collection of Microorganism and Cell Cultures (Germany). The bacterium was grown on Petri plates containing $4 \mathrm{~g} / \mathrm{L}$ glucose, $4 \mathrm{~g} / \mathrm{L}$ yeast extract, $10 \mathrm{~g} / \mathrm{L}$ malt extract, $2 \mathrm{~g} / \mathrm{L} \mathrm{CaCO} \mathrm{Ca}_{3}$ and $12 \mathrm{~g} / \mathrm{L}$ agar agar at $\mathrm{pH} 7.2-7.4$ for 5 days at $28-30^{\circ} \mathrm{C}$. Then, the plates were maintained at $4{ }^{\circ} \mathrm{C}$ and sub-cultured every 3 weeks.

Staphyloccocus epidermidis DSMZ 1798 was obtained from the German Collection of Microorganism and Cell Cultures (Germany). This bacterium was used as a test organism for the determination of the neomycin produced by $S$. fradiae applying the Kirby-Bauer test. S. epidermidis was grown on Petri plates containing $10 \mathrm{~g} / \mathrm{L}$ peptone from caseine, $5 \mathrm{~g} / \mathrm{L}$ yeast extract, $5 \mathrm{~g} / \mathrm{L}$ glucose, $5 \mathrm{~g} / \mathrm{L}$ $\mathrm{NaCl}$ and $5 \mathrm{~g} / \mathrm{L}$ agar agar at $\mathrm{pH} 7.2-7.4$ for 5 days at $28-30^{\circ} \mathrm{C}$. Then, the plates were maintained at $4{ }^{\circ} \mathrm{C}$ and sub-cultured every 1-2 weeks.

\subsection{Supports}

\subsubsection{Inert support}

Cubes (edge size $1.0 \mathrm{~cm}$ ) of nylon sponge (Scotch Brite, $3 \mathrm{M}$ Spain, S.A.) were used as inert supports. Prior to use, the cubes of nylon sponge were pre-treated by boiling for $10 \mathrm{~min}$ and washing thoroughly three times with distilled water (Linko, 1991). Thereafter, the cubes were dried in an oven at $30^{\circ} \mathrm{C}$.

\subsubsection{Natural support}

Orange fruits (Citrus sinensis) were obtained from a local market and the peelings were collected after the normal human consumption of the fruit flesh. The orange peelings are mainly composed of both soluble and insoluble carbohydrates. The soluble sugars in orange peelings are glucose, fructose and sucrose. The insoluble polysaccharides in cell walls of orange peelings are composed of pectin, cellulose and hemicellulose. They also contain minor amounts of organic acids, mainly citric, malic, malonic and oxalic, proteins, mineral ions, phenolic compounds and polyols (Grohmann et al., 1995). Prior to use, the orange peelings (size $1.5 \mathrm{~cm} \times 1.5 \mathrm{~cm}$ ) were pre-treated as follows: they were first soaked for $1 \mathrm{~h}$ in $30 \mathrm{~mL}$ of $\mathrm{KOH} 83.17 \mathrm{mM}$ (10 g of fresh peelings) to neutralise organic acids (Stredansky and Conti, 1999). Then, they were thoroughly washed with distilled water and dried in an oven at $30^{\circ} \mathrm{C}$.

Prior to use, all the supports were autoclaved at $121^{\circ} \mathrm{C}$ for $20 \mathrm{~min}$

\subsection{Inoculum preparation}

At the 5 th day of grown of $S$. fradiae, $5 \mathrm{~mL}$ of $\mathrm{KCl}$ solution $(20 \mathrm{~g} / \mathrm{L})$, previously sterilised, were added to the Petri plates. The spores were scraped and transferred into $100-\mathrm{mL}$ cotton-plugged Erlenmeyer flasks containing $30 \mathrm{~mL}$ of inoculum medium, which was composed of $10 \mathrm{~g} / \mathrm{L}$ glucose, $20 \mathrm{~g} / \mathrm{L}$ soya peptone, $5 \mathrm{~g} / \mathrm{L}$ meet extract, $5 \mathrm{~g} / \mathrm{L} \mathrm{NaCl}$ and $10 \mathrm{mg} / \mathrm{LZnSO}_{4} 7 \mathrm{H}_{2} \mathrm{O}$ in tap water (initial $\mathrm{pH}$ 7.4). The flasks were incubated on an orbital shaker at $200 \mathrm{rpm}$ and $30^{\circ} \mathrm{C}$ for $48 \mathrm{~h}$. After centrifugation ( $5000 \mathrm{rpm}, 20 \mathrm{~min}$ ), the resulting pellets were washed with a sterile solution of $\mathrm{KCl}(20 \mathrm{~g} / \mathrm{L})$ several times and re-suspended in $30 \mathrm{~mL}$ of the same saline solution. This cell suspension was used as inoculum in the experiments.

\subsection{Submerged fermentation}

The experiments were performed in 500-mL cotton-plugged Erlenmeyer flasks containing $90 \mathrm{~mL}$ of culture medium and $10 \mathrm{~mL}$ of inoculum. The composition of the culture medium was the same as that used for the inoculum. The flasks were incubated on an orbital shaker at $200 \mathrm{rpm}$ and $28-30^{\circ} \mathrm{C}$ for 10 days. Samples were only taken on days $4,6,8$ and 10 of incubation. At the end of fermentation, the entire content of each flask was centrifuged at $5000 \mathrm{rpm}$ for $20 \mathrm{~min}$. The pellet was collected for biomass determination by means of its dry weight and the supernatant for the determination of neomycin by applying the Kirby-Bauer test.

\subsection{Semi-solid-state fermentation}

Experiments were conducted in 250-mL cotton-plugged Erlenmeyer flasks containing $2 \mathrm{~g}$ of nylon sponge cubes or $15 \mathrm{~g}$ of orange peelings, according to the experiment, $30 \mathrm{~mL}$ of culture medium and $3 \mathrm{~mL}$ of inoculum. The amount of support used was selected according to previous experiments. The composition of the culture medium was the same as that used for the inoculum. The flasks were incubated in static conditions at $28-30^{\circ} \mathrm{C}$ and in complete darkness for 12 days. Samples were taken on days $4,6,8,10$ and 12 . 

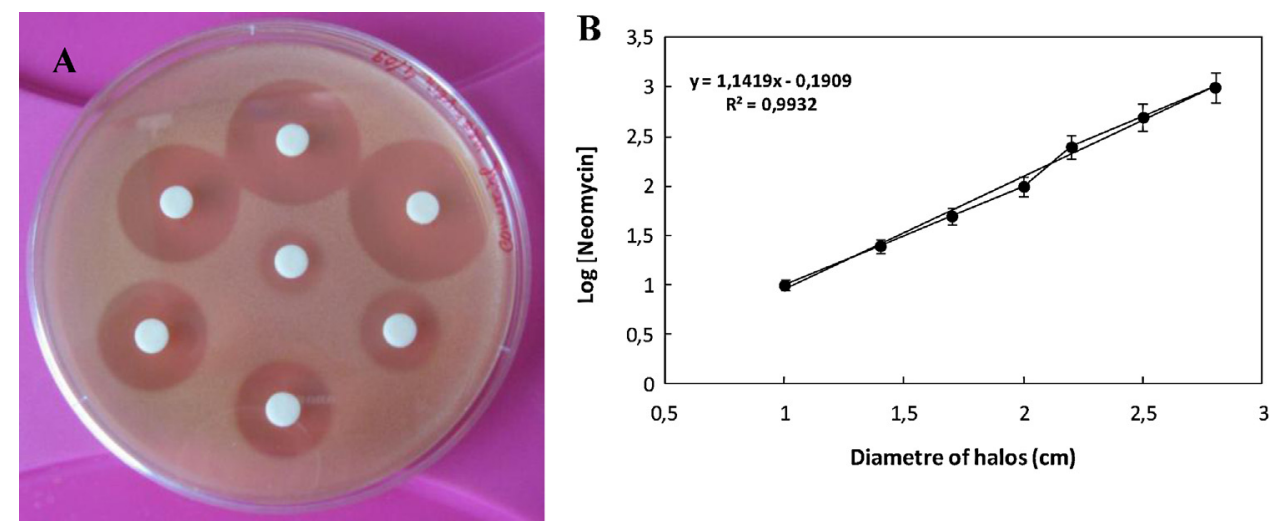

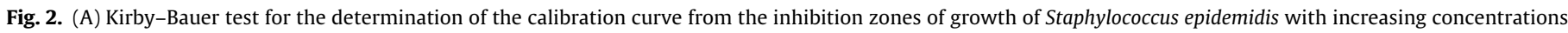
of sulphate neomycin from 10 to $1000 \mu \mathrm{g} / \mathrm{mL}$. (B) Determined calibration curve.

Neomycin was extracted by adding $5 \mathrm{~mL}$ of phosphate buffer $(\mathrm{pH}$ 8.0) in each Erlenmeyer flask (Adinarayana et al., 2003) in order to get the liquid retained by the supports. Then, the flasks were kept on an orbital shaker at $200 \mathrm{rpm}$ for $1 \mathrm{~h}$ and afterwards the content of each flask was centrifuged ( $5000 \mathrm{rpm}, 20 \mathrm{~min}$ ) and filtered $(0.22 \mu \mathrm{m})$. This filtrate was used to determine the content of neomycin by the agar diffusion method, also known as Kirby-Bauer test. In this case the biomass could not be determined since it was tightly bound to the support.

All the experiments were done in triplicate and mean values were reported.

\subsection{Analytical determinations}

Reducing sugars were measured by the dinitrosalicylic (DNS) acid method, using D-glucose as a standard, according to Miller (1959).

Neomycin concentration was determined by the standard agar diffusion method using S. epidermidis as a test organism (Grove and Randall, 1955). Antibiotic-assay discs (Aldrich Whatman ${ }^{\circledR}$ Schleicher \& Schuell ${ }^{\circledR}$ ) were impregnated with $50-90 \mu \mathrm{L}$ of sample, placed on agar plates and the inhibition zones measured (in $\mathrm{cm}$ ) after $24 \mathrm{~h}$ of incubation at $30^{\circ} \mathrm{C}$. Standard neomycin sulphate (Vetranal, Sigma-Aldrich) was used to construct the calibration curve (Fig. 2).

\section{Results and discussion}

\subsection{Neomycin production by SmF cultures of S. fradiae}

In Fig. 3A-C the halos corresponding to neomycin inhibition for the samples collected on days 4 to 10 , can be observed.

Fig. 3D shows the evolution of the reducing sugars and the neomycin production by $S$. fradiae grown under SmF conditions. It can be seen that the neomycin production started after glucose, measured as reducing sugars, began to decrease. This indicates that neomycin production by $S$. fradiae is triggered by carbon depletion.

The maximal concentration of neomycin was detected on the 10 th cultivation day with a value of about $250 \mu \mathrm{g} / \mathrm{mL}$ (Fig. 3D). However, the concentration determined on the 6th cultivation day was higher than that determined for day 8 . This is due to bacterial growth that was lower on the 8th cultivation day than on the 6th one as showed the biomass values in Fig. 3E. Consequently concentrations of neomycin and reducing sugars were also lower on the 8th cultivation day.

Fig. $3 \mathrm{C}$ shows the halos corresponding to neomycin inhibition for the samples collected on the days 8 and 10 . It can be seen that the bacterium grows forming independent colonies, unlike the other Petri plates where the growth is more homogeneous. This was likely due to the heterogeneous diffusion of the antibiotic on the Petri plates due to its high concentration.

\subsection{Neomycin production by semi-solid-state fermentation cultures of S. fradiae}

In the nylon sponge cultures, the first sample was collected on the 2 nd day and the last one on the 12th day of incubation. The neomycin production started very early (2nd day) and glucose, measured as reducing sugars, was not totally depleted. Then, the neomycin production increased peaking on the 10 th day with a value of $13,903 \mu \mathrm{g} / \mathrm{mL}$ (Fig. 4A). This value is 55 -fold higher than that obtained in SmF. In addition, it is about 4-fold higher than that reported by Ohta et al. (1995) by $S$. fradiae grown in a stirred-tank reactor and by Vastrad and Neelagund (2011) by S. fradiae grown on apple pomace under optimised SSF conditions.

In the orange peelings cultures, neomycin production did not start until the 10th cultivation day (Fig. 4B). The increase in reducing sugars on the 2 nd day was likely due to the hydrolysis of the sugars contained in the orange peelings during autoclaving. The consumption of glucose, measured as reducing sugars, was much slower than in the nylon sponge cultures. Glucose concentration, measured as reducing sugars, from day 4 onwards was higher in orange peeling cultures than in nylon sponge ones. This might be due to the reduction of some of the carbohydrates contained in the peelings by the bacterium.

The amount of neomycin produced $(281.4 \mu \mathrm{g} / \mathrm{mL}$ on days 10 and 12), although slightly higher than that obtained in SmF, was much lower than the one achieved operating with nylon sponge as a support. In addition, the lag phase lasted 9 days. Therefore, orange peelings are not a suitable support for the production of neomycin by $S$. fradiae under semi-solid-state fermentation conditions. This indicates the importance of the support selection in semi-solid-state cultivation. Fig. 4C and D shows the halos corresponding to neomycin inhibition for the samples collected on days 2, 4 and 6 from nylon sponge (EN) and orange peeling (CL) cultures. The uneven growth of $S$. epidermidis on the agar plates was likely due to the heterogeneous diffusion of the antibiotic on the agar plates caused by its high concentration.

The higher neomycin production obtained using cubes of nylon sponge as supports was likely due to the high porosity of the nylon sponge which allowed a better diffusion of oxygen and nutrients into the cultures, thus favouring the production of the antibiotic.

The higher cost of using an inert support can be overcome by the advantages it presents over a natural one such as decreasing the cost of the downstream processing, improving process 

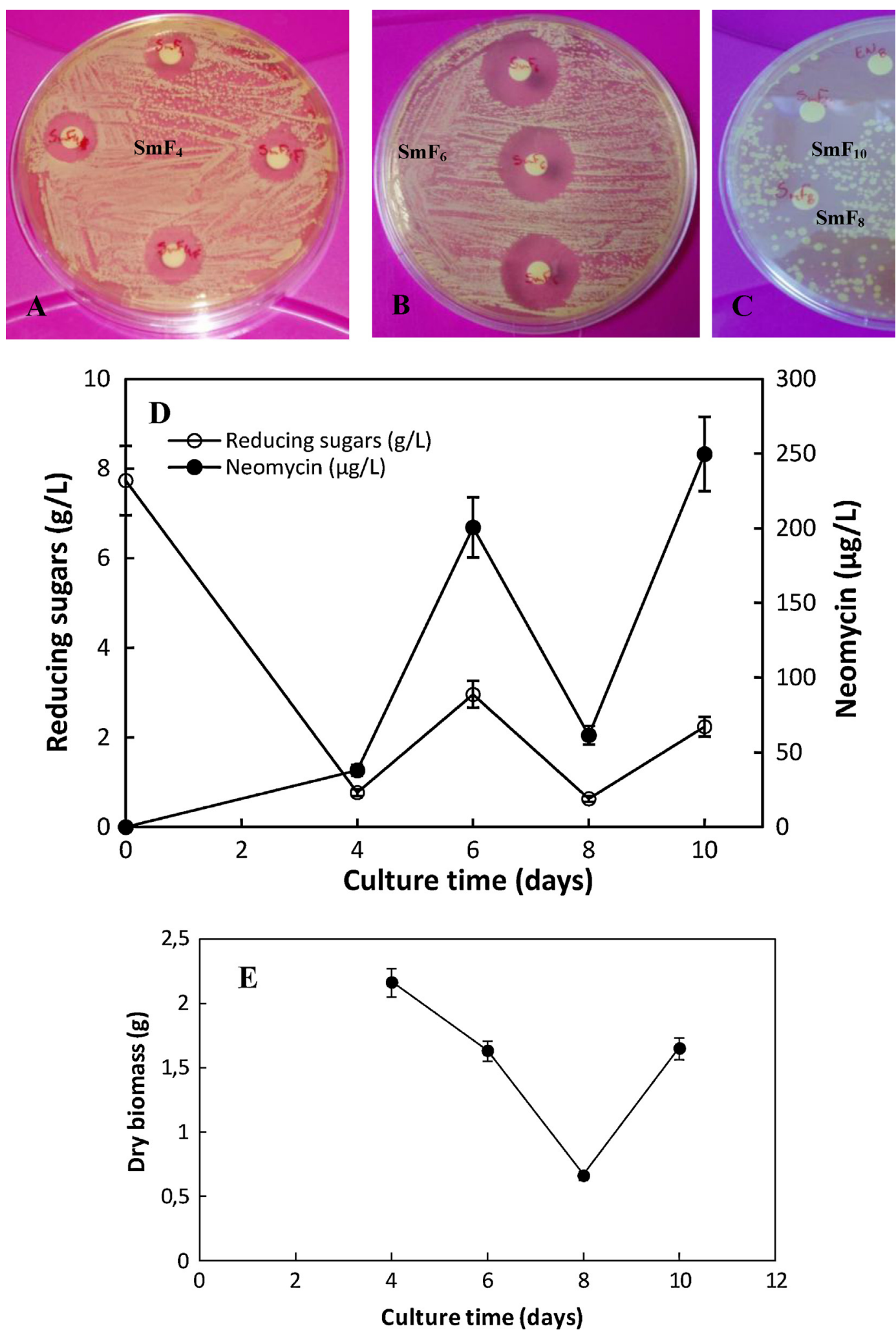

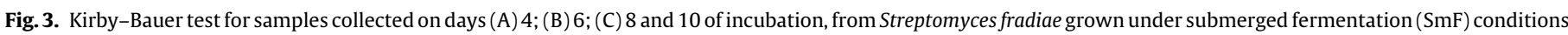

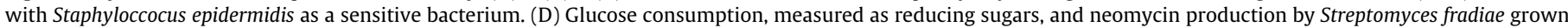
under submerged fermentation conditions. (E) Biomass determined as dry weight. 

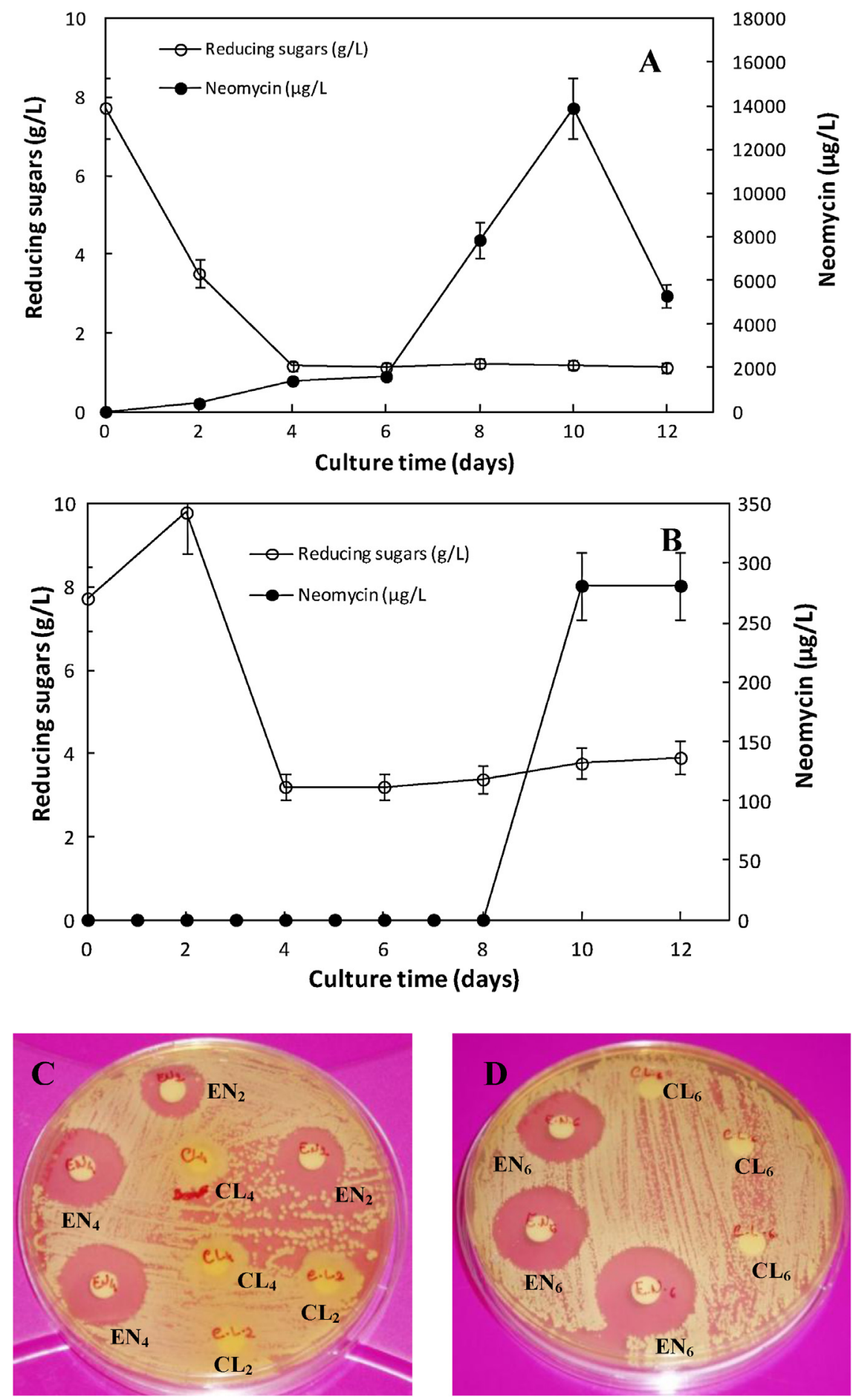

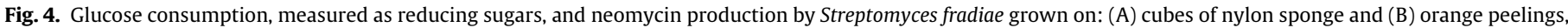

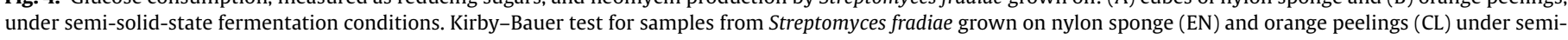
solid-state fermentation conditions for (C) the 2nd, 4th days and (D) 6th day.

control and monitoring and enhancing process consistency (Ooijkaas et al., 2000). In addition, it allows the design of suitable production media. Moreover, as the physical structure of the inert support is maintained throughout the process it can be reutilised (Rodríguez-Couto, 2012).

\section{Conclusions}

SmF is usually used for the commercial production of neomycin. The results of this paper show that semi-solid-state fermentation operating with an inert support, such as nylon sponge, increased considerably the production of neomycin by $S$. fradiae with a maximum antibiotic production of $13,903 \mu \mathrm{g} / \mathrm{mL}$. This value is 55 -fold higher than that obtained in SmF conditions. Therefore, it can be concluded that semi-solid-state fermentation holds great promise for neomycin production.

\section{Acknowledgements}

IM acknowledges the Erasmus mobility programme. 
200

I. Machado et al. / Journal of Biotechnology 165 (2013) 195-200

References

Waksman, S.A., Lechevalier, H.A., 1949. Neomycin, a new antibiotic active against streptomycin-resistant bacteria, including tuberculosis organisms. Science 109, 305-307.

Sambamurthy, K., Ellaiah, P., 1974. A new Streptomycete producing neomycin (B\&C) complex -S. marinensis. Part I. Hindustan Antibiotics Bulletin 17, 24-27.

Yuan, L.L., Wei, H.P., Feng, H.T., Li, S.F.Y., 2006. Rapid analysis of native neomycin components on a portablecapillary electrophoresis system with potential gradient detection. Analytical and Bioanalytical Chemistry 385, 1575-1579.

Ellaiah, P., Srinivasulu, B., Adinarayana, K., 2004. Optimisation studies on neomycin production by a mutant strain of Streptomyces marinensis in solid state fermentation. Process Biochemistry 39, 529-534.

Castilho, L.R., Polato, C.M.S., Baruque, E.A., Sant'Anna Jr., G.L., Freire, D.M.G., 2000 Economic analysis of lipase production by Penicillium restrictum in solid-state and submerged fermentations. Biochemical Engineering Journal 4, 239-247.

Osma, J.F., Toca-Herrera, J.L., Rodríguez-Couto, S., 2011. Cost analysis in laccase production. Journal of Environmental Management 92, 2907-2912.

Pandey, A., 1992. Recent process developments in solid-state fermentation. Process Biochemistry 27, 109-117.

Pandey, A., Soccol, C.R., Mitchell, D.A., 2000. New developments in solid-state fermentation: I-bioprocesses and products. Process Biochemistry 35, 1153-1169.

Rodriguez-Couto, S., Gundin, M., Lorenzo, M., Sanroman, A., 2002. Screening of supports and inducers for laccase production by Trametes versicolor in semisolid-state conditions. Process Biochemistry 38, 249-255.

Economou, C.N., Makri, A., Aggelis, G., Pavlou, S., Vayenas, D.V., 2010. Semi-solid state fermentation of sweet sorghum for the biotechnological production of single cell oil. Bioresource Technology 101, 1385-1388.
Linko, S., 1991. Production of lignin peroxidase by immobilized Phanerochaete chrysosporium. Ph.D. Thesis, Helsinki University of Technology, Espoo, Finland.

Grohmann, K., Cameron, R.G., Buslig, B.S., 1995. Fractionation and pretreatment of orange peel by dilute acid hydrolysis. Bioresource Technology 54 $129-141$.

Stredansky, M., Conti, E., 1999. Xanthan production by solid state fermentation. Process Biochemistry 34, 581-587.

Adinarayana, K., Ellaiah, P., Srinivasulu, B., Bhavani Devi, R., Adinarayana, G., 2003. Response surface methodological approach to optimize the nutritional parameters for neomycin production by Streptomyces marinensis under solid-state fermentation. Process Biochemistry 38, 1565-1572.

Miller, G.L., 1959. Use of dinitrosalicylic acid reagent for determination of reducing sugar. Analytical Chemistry 31, 426-428.

Grove, D.C., Randall, W.A., 1955. Assay Methods of Antibiotics: A Laboratory Manual. Medical Encyclopedia Inc., New York.

Ohta, N., Park, Y.S., Yahiro, K., Okabe, M., 1995. Comparison of neomycin production from Streptomyces fradiae cultivation using soybean oil as the sole carbon source in an air-lift bioreactor and a stirred-tank reactor. Journal of Fermentation and Bioengineering 79, 443-448.

Vastrad, B.M., Neelagund, S.E., 2011. Optimization and production of neomycin from different agro industrial wastes in solid state fermentation. International Journal of Pharmaceutical Sciences and Drug Research 3, 104-111.

Ooijkaas, L.P., Weber, F.J., Buitelaar, R.M., Tramper, J., Rinzema, A., 2000. Defined media and inert supports: their potential as solid-state fermentation production systems. Trends in Biotechnology 18, 356-360.

Rodríguez-Couto, S., 2012. A promising inert support for laccase production and decolouration of textile wastewater by the white-rot fungus Trametes pubescens. Journal of Hazardous Materials 233-234, 158-162. 